\title{
Parâmetros de conforto térmico e fisiológico de ovinos Santa Inês, sob diferentes sistemas de acondicionamento
}

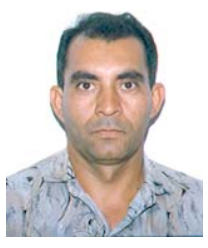

Francisco M. M. Oliveira' ${ }^{1}$ Renilson T. Dantas ${ }^{2}$, Dermeval A. Furtado ${ }^{3}$, Jose W. B. Nascimento ${ }^{3} \&$ Ariosvaldo N. Medeiros ${ }^{4}$

${ }^{1}$ Freelance. Rua Melões de São Caetano, 185, CEP 58109-440. Campina Grande, PB. Fone: (83) 3339-6060. (Foto) ${ }^{2}$ DCA/UFCG. Av. Aprígio Veloso, 882. CEP 58109-930. Campina Grande, PB. Fone: (83) 3310-1201 E-mail: renilson@dca.ufcg.edu.br

${ }^{3}$ DEAg/UFCG. Fone: (83) 3310-1486. E-mail: dermeval@deag.ufcg.edu.br, wallace@deag.ufcg.edu.br

${ }^{4}$ DZ/UFPB. Campus II da UFPB. Fone: (83) 3362-2504 E-mail: medeiros@cca.ufpb.br

Protocolo $30-29 / 3 / 2005$ - Aprovado em 16/19/2005

Resumo: Através do presente trabalho, objetivou-se determinar os parâmetros fisiológicos e produtivos e os índices de conforto térmico em ovinos da raça Santa Inês, criados em dois apriscos, um coberto com telha de barro (TBA) e o outro com telha de fibrocimento (TFC), no município de São João do Cariri, nos meses de agosto a outubro de 2003. Utilizaram-se 20 animais machos, castrados e distribuídos em baias individuais. Os índices ambientais analisados foram a temperatura ambiente, do globo negro, umidade relativa do ar, velocidade do vento, índice de temperatura do globo negro e umidade e carga térmica de radiação. Os índices fisiológicos se referem à temperatura retal (TR) e à freqüência respiratória (FR) e os índices produtivos, o ganho de peso, conversão alimentar e consumo de matéria seca. Os apriscos com TBA e TFC não apresentaram diferença significativa nos índices de conforto térmico, no período da manhã nem da tarde. Comparando-se esses períodos, observou-se aumento nos índices para o período da tarde. Os animais conseguiram manter a TR dentro dos limites normais e apresentaram, no período da tarde, uma FR superior às encontradas pela manhã, sendo que os índices produtivos não variaram entre os sistemas analisados e foram considerados satisfatórios.

Palavras-chave: bioclimatologia, ruminantes, ambiência

\section{Parameters of thermal and physiological comfort of Santa Inês sheep in different conditioning systems}

\begin{abstract}
The objetive of this work was to determine physiological and productive parameters and the thermal comfort indices in "Santa Inês" breed of sheep created in two different shelters, one being covered with clay tile (TBA) and the other covered with cement fiber tiles (TFC), in the municipality of São João do Cariri, Paraíba State, Brazil, during the months of August to October 2003. Twenty castrated male sheeps were distributed in individual bays. The environmental indices analyzed were the temperature and humidity of the black globe index and the thermal charge of radiation index. The data used were the air temperature, black globe temperature, relative humidity and wind velocity. The physiological indices reffered were the rectal temperature (TR) and the respiratory frequency (FR) and the production indices refered were the weight gain, food conversion and the dry matter consumption. The shelters with TBA and TFC did not present significant differences in indices of thermal comfort, neither in the morning nor in the evening periods. There was a little increase in the indices during the evening period. The animals could maintain a TR within the normal limits and during the evening period the FR was higher than that in the morning. The production indices did not vary between the systems analyzed and were considered satisfactory.
\end{abstract}

Key words: thermal comfort, air temperature, environment 


\section{INTRODUÇÃO}

O Brasil possui um efetivo em torno de 8,7 milhões de cabeças de ovinos, dos quais $90 \%$ se encontram na região Nordeste, formado principalmente de animais tipo nativo e sem raça definida (SRD), de notável rusticidade e baixa produtividade (Silva et al., 1993). Apesar do reconhecido valor sócioeconômico da ovinocultura para o nordeste brasileiro, a maior parte dos animais criados nesta região apresenta baixos índices de desempenho produtivo, com peso vivo aos 100 dias, de $8 \mathrm{~kg}$, e peso médio da carcaça de machos com 1 ano de 10 $\mathrm{kg}$, fêmeas apresentando $80 \%$ de parição (partos ao ano por matriz) e prolificidade de 1,3 crias por parto (BNB, 1999).

A baixa produção é resultado de múltiplos efeitos do ambiente tropical, que inclui efeitos indiretos, como baixa qualidade dos alimentos, baixo potencial genético dos animais, além do efeito direto do estresse ambiental, notadamente os elementos climáticos, como temperatura do ar, umidade e radiação solar, os quais freqüentemente se encontram acima do ideal para ótimo desempenho do rebanho (Viana, 1990).

Os ovinos, assim como outros mamíferos e aves, são homeotérmicos, ou seja, são animais que têm a capacidade de controlar, dentro de uma estreita margem, a temperatura corporal (Hafez, 1995). Este mecanismo, entretanto, é eficiente quando a temperatura ambiente está dentro de certos limites, o que demonstra a importância de se manter as instalações com temperaturas ambientais próximas às das condições de conforto. Segundo Nããs (1989) o ideal é uma umidade relativa média de $75 \%$ e temperatura entre 4 a $30^{\circ} \mathrm{C}$. Baeta \& Souza (1997) recomendam que a zona de conforto para ovinos deve situar-se entre 20 e $30^{\circ} \mathrm{C}$, sendo a temperatura efetiva crítica superior a $34^{\circ} \mathrm{C}$. McDowel (1972) preconizou, como condições ideais para criação de animais domésticos, umidade relativa do ar entre 60 e $70 \%$ e ventos com velocidade de 1,3 a $1,9 \mathrm{~m} \mathrm{~s}^{-1}$. Mota (2001) descreve que, segundo dados da equipe de conforto ambiental da UNICAMP, as condições de ambiente para vacas em lactação, conforme valor da temperatura do globo negro, se situam da seguinte forma: entre 7 e $27^{\circ} \mathrm{C}$ ótimo; entre 27 e $34^{\circ} \mathrm{C}$, regular e acima de $35^{\circ} \mathrm{C}$, crítico. Rosa (1984) em trabalhos com frangos de corte encontrou valores da carga térmica de radiação de 515,4 e $498,3 \mathrm{~W} \mathrm{~m}^{-2}$ para galpões com telhas de fibrocimento e barro, respectivamente.

A temperatura retal é uma boa indicadora da temperatura corporal. Segundo Brion (1964) a temperatura retal média de ovinos adultos varia de 39,0 a $40,0^{\circ} \mathrm{C}$. O impacto do calor sobre as variáveis fisiológicas resulta em um aumento percentual de $3 \%$ na temperatura retal e de $194 \%$ na freqüência respiratória, com alterações, respectivamente, de 38,6 para $39,9^{\circ} \mathrm{C}$ e de 32 para 94 movimentos por minuto (McDowell, 1972). De acordo com Santos et al. (2005) e Souza et al. (2005), a temperatura retal e a freqüência respiratória dos animais são afetadas pelo período do dia, cujos animais mostraram temperatura retal menor no período da manhã, quando comparados com o período da tarde.

No nordeste do Brasil, a produtividade da ovinocultura é afetada negativamente pelas estiagens prolongadas e secas periódicas que ocorrem na região. Barros \& Simplício (1996) constataram que durante a época chuvosa não há limitações nutricionais, mas na época seca ocorre redução na capacidade de suporte forrageiro afetando, quantitativa e qualitativamente, a disponibilidade de forragens nas pastagens, tornando-se o confinamento uma alternativa e, entre as raças ovinas predominantes no Nordeste para produção de carne, os animais Santa Inês são os que alcançam os melhores ganhos de peso sob confinamento.

Perez et al. (1995) utilizando ovelhas da raça Santa Inês, acasaladas com machos da mesma raça e suplementadas com concentrados, encontraram um ganho de peso diário para os machos de 211 e de $129 \mathrm{~g} \mathrm{dia}^{-1}$ para as fêmeas. Barros et al. (1999) em estudos em que utilizaram três dietas alimentares, trabalhando com animais da raça Santa Inês e cruzados, acima de 112 dias de idade, em um experimento com duração de 55 dias constataram, para os animais Santa Inês, ganhos diários médios de $160 \mathrm{~g} \mathrm{dia}^{-1}$, com variação entre $95 \mathrm{a} 267 \mathrm{~g} \mathrm{dia}^{-1}$, sendo que esta variação pode estar associada, em grande parte, à heterogenicidade dos genótipos dos animais e à qualidade da alimentação fornecida. Conduziu-se o presente estudo com o propósito de determinar a influência de dois sistemas de acondicionamento térmico na temperatura interna da cobertura, nos parâmetros fisiológicos e produtivos e nos índices de conforto térmico, em ovinos da raça Santa Inês.

\section{MATERIAL E MÉTODOS}

O trabalho foi realizado na cidade de São João do Cariri, região semi-árida do Estado da Paraíba, no período de agosto a outubro de 2003. Utilizaram-se dois apriscos, um coberto com telha de alvenaria (TBA) e outro coberto com telha de fibrocimento (TFC) além de divisórias das baias, com arame galvanizado. Cada aprisco tinha $52,5 \mathrm{~m}^{2}$ de área, dividido em 10 baias, cada uma com $3,75 \mathrm{~m}^{2}$, corredor central de $2,0 \mathrm{~m}$ de largura, pé direito de $2,8 \mathrm{~m}$ e orientação do eixo principal no sentido Leste-Oeste. Trabalhou-se com 20 animais da raça Santa Inês, todos machos castrados, distribuídos em baias individuais, providas de comedouros e bebedouros.

A temperatura interna da telha foi medida com termômetro infravermelho, em três locais diferentes de cada galpão, na parte da frente, no meio e na parte posterior do aprisco, às $9 \mathrm{e}$ $15 \mathrm{~h}$. Realizaram-se, durante o período experimental e nos mesmos horários, as leituras da temperatura do ar (Tbs), temperatura de bulbo úmido (Tbu), temperatura do globo negro (Tgn) e velocidade do vento (V) e, com os dados, calcularamse a umidade relativa do ar (UR), o índice de temperatura do globo negro e umidade (ITGU) e a carga térmica de radiação (CTR). Os equipamentos estavam localizados a nível do centro de massa dos ovinos.

Os índices fisiológicos foram medidos às $9 \mathrm{e} 15 \mathrm{~h}$, e a medição da temperatura retal (TR) foi realizada através da introdução de um termômetro clínico veterinário, com escala até $44{ }^{\circ} \mathrm{C}$, diretamente no reto do animal, a uma profundidade de $5 \mathrm{~cm}$, permanecendo por $2 \mathrm{~min}$; após este tempo, fazia-se a leitura. A freqüência respiratória (FR) foi realizada através da auscultação direta das bulhas, a nível da região laringo-traqueal, com auxílio de um estetoscópio, contando-se o número de movimentos durante $15 \mathrm{~s}$, e o valor obtido foi multiplicado por 4, obtendose a freqüência respiratória em movimentos por minuto. 
Para obtenção da temperatura superficial utilizou-se o termômetro infravermelho, cujas leituras foram realizadas a cada duas horas, das 7 às $17 \mathrm{~h}$, na cabeça, no costado e nas pernas dos animais. Os índices produtivos analisados foram: ganho de peso total (GPT), ganho de peso diário (GPD), conversão alimentar (CA) e o consumo de matéria seca (CMS). O GPT foi calculado pela diferença entre o peso final e o peso dos animais no inicio do experimento. O GPD foi encontrado dividindo-se o GPT pelo número de dias do experimento. A CA é a relação entre a quantidade de ração consumida e o ganho de peso correspondente. $\mathrm{O}$ consumo de matéria seca é a relação entre o consumo de matéria seca e o ganho de peso correspondente.

O delineamento experimental utilizado para análise da temperatura da telha foi o inteiramente ao acaso, em arranjo fatorial $2 \times 3 \times 3$ ( 2 sistemas de acondicionamento, 3 posições na face interna e externa do telhado, 3 horários). As análises dos dados obtidas dos índices de conforto térmico, produtivos e fisiológicos, foram realizadas pelo teste t de Student, de acordo com Ferreira (1996).

\section{RESULTADOS E DISCUSSÃO}

As médias das variáveis ambientais analisadas estão apresentadas na Tabela 1, na qual se observa que nos períodos da manhã e da tarde, a temperatura do ar não apresentou diferença significativa $(\mathrm{P}>0,05)$ entre os sistemas mas, sim, entre o período da manhã e o da tarde, em ambos os sistemas, a nível de $5 \%$ de probabilidade. Analisando-se a temperatura da manhã, nota-se que ela esteve, nos dois sistemas, dentro da zona de conforto térmico, porém no período da tarde a temperatura esteve nos dois sistemas, fora da zona de termoneutralidade sem, no entanto, ultrapassar a temperatura crítica efetiva superior, que é de $35^{\circ} \mathrm{C}$ (Baêta \& Sousa, 1997). Esses valores foram semelhantes aos encontrados por Souza et al. (2005) ou seja, valores dentro da zona de conforto térmico no período da manhã e desconforto no período da tarde, embora inferiores aos valores indicados por Silva et al. (2004) e Santos et al. (2005) em trabalhos na região semi-árida nordestina.

Com vistas à temperatura do globo negro (Tgn), observase, à semelhança da TA, tanto no sistema TBA ou TFC, diferença significativa a nível de $5 \%$ de probabilidade apenas

Tabela 1. Médias* das variáveis ambientais internas, no horário das 9:00 e $15 \mathrm{~h}$, nos dois sistemas de acondicionamento térmico

\begin{tabular}{|c|c|c|c|c|}
\hline \multirow{3}{*}{ Variáveis ambientais } & \multicolumn{4}{|c|}{ Sistemas } \\
\hline & \multicolumn{2}{|c|}{$\begin{array}{c}\text { Telha de } \\
\text { barro }\end{array}$} & \multicolumn{2}{|c|}{$\begin{array}{l}\text { Telha de } \\
\text { fibrocimento }\end{array}$} \\
\hline & Manhã & Tarde & Manhã & Tarde \\
\hline Temperatura do ar, ${ }^{\circ} \mathrm{C}$ & $25,4 \mathrm{a}$ & $29,5 \mathrm{~b}$ & $25,8 \mathrm{a}$ & $31,1 \mathrm{~b}$ \\
\hline Temp. do globo negro, ${ }^{\circ} \mathrm{C}$ & $28,8 \mathrm{a}$ & $32,4 \mathrm{~b}$ & $29,6 \mathrm{a}$ & $35,6 \mathrm{~b}$ \\
\hline Velocidade do vento, $\mathrm{m} \mathrm{s}^{-1}$ & $1,9 \mathrm{a}$ & $2,0 \mathrm{a}$ & $2,0 \mathrm{a}$ & $2,0 \mathrm{a}$ \\
\hline Umidade relativa UR, \% & $59,8 \mathrm{a}$ & $38,4 \mathrm{~b}$ & $62,2 \mathrm{a}$ & $39,8 \mathrm{~b}$ \\
\hline $\begin{array}{l}\text { Índice de temperatura de } \\
\text { globo negro e umidade }\end{array}$ & $77,1 \mathrm{a}$ & $82,2 \mathrm{~b}$ & $76,2 \mathrm{a}$ & $81,3 \mathrm{~b}$ \\
\hline Carga térm. radiante, $\mathrm{W} \mathrm{m}^{-2}$ & $556,9 \mathrm{a}$ & $596,0 \mathrm{~b}$ & $529,8 \mathrm{a}$ & $575,9 \mathrm{~b}$ \\
\hline
\end{tabular}

entre os turnos manhã e tarde. Segundo a classificação citada por Mota (2001) o ambiente, tanto da manhã como o da tarde, pode ser classificado como regular, já que a situação crítica pode ser considerada com a Tgn acima de $35{ }^{\circ} \mathrm{C}$. Essas temperaturas foram idênticas às apresentadas por Souza et al. (2005) que, em trabalhos no sertão paraibano, encontram valores médios de Tgn de 24,7 e $32,4{ }^{\circ} \mathrm{C}$ para os turnos da manhã e tarde, respectivamente. Os valores encontrados pela manhã foram semelhantes aos apresentados por Silva et al. (2004) mas, no periodo da tarde, foram inferiores aos valores encontrados por esses autores.

Em relação à velocidade do vento, esta não diferiu estatisticamente dentro dos sistemas nem dentro dos turnos, ficando esses valores acima da velocidade mínima recomendada por McDowel (1972), que é de 1,9 $\mathrm{m} \mathrm{s}^{-1}$, e abaixo da faixa máxima recomendada.

Observa-se, no que diz respeito à umidade relativa do ar (UR) diferença apenas entre os turnos, enquanto no período da tarde esteve abaixo do recomendado por Baeta \& Souza (1997), cuja UR deve situar-se entre 40 e 70\%. Esses valores foram semelhantes aos encontrados por Souza et al. (2005) que, em trabalhos no sertão paraibano, descrevem valores médios de 61,0 e 41,0\% de UR, para os turnos da manhã e tarde, respectivamente. Os valores de UR, encontrados no período da manhã e no da tarde, foram superiores aos relatados por Silva et al. (2004) e Santos et al. (2005).

Analisando-se o ITGU, nota-se que, à semelhança da TA e Tgn, tanto no sistema TBA como no TFC, ocorreu diferença significativa a nível de $5 \%$ de probabilidade, entre os turnos manhã e tarde. Os valores da manhã podem, em ambos os sistemas, ser caracterizados como situação de conforto, mas os índices encontrados no período da tarde podem sê-lo como situação de alerta (Baeta \& Sousa, 1997). Os valores encontrados no período da manhã foram semelhantes aos indicados por Silva et al. (1993) e Souza et al. (2005), porém os valores encontrados no período da tarde foram superiores aos mostrados pelo último autor. Comparando-se os valores encontrados com os relatados por Silva et al. (2004), em trabalhos na região semi-árida paraibana, nas épocas quente e seca, os valores de ITGU, tanto da manhã como da tarde, foram inferiores aos relatados pelos autores, de 79,5 e 84,9, para o período da manhã e da tarde, respectivamente.

Vê-se que a CTR apresentou, nos sistemas TBA como no TFC, diferença significativa a nível de $5 \%$ de probabilidade entre os turnos manhã e tarde. Tomando-se por base os valores da CTR, citados por Rosa (1984), conclui-se que os valores encontrados nos dois sistemas e nos dois horários analisados foram superiores aos recomendados, caracterizando situação de desconforto térmico, os valores da manhã e os da tarde foram superiores aos encontrados por Rosa (1984) e Furtado et al. (2002) em trabalhos com frango de corte, seja em telhas de barro como de fibrocimento.

A temperatura média interna das telhas nos diferentes sistemas de acondicionamento térmico, está apresentada na Tabela 2, na qual se observa que não houve diferença significativa em nível de $5 \%$ de probabilidade, entre os dois tipos de cobertura mas, sim, entre os turnos da manhã e tarde. Em todas as situações, a temperatura da superfície interna do 
Tabela 2. Médias* da temperatura interna das telhas de barro e de fibrocimento

\begin{tabular}{lcc}
\hline \multirow{2}{*}{ Sistemas } & \multicolumn{2}{c}{ Turnos } \\
\cline { 2 - 3 } & Manhã & Tarde \\
\hline Telha de Barro & $30,7 \mathrm{aA}$ & $36,1 \mathrm{bA}$ \\
Telha de Fibrocimento & $31,9 \mathrm{aA}$ & $37,5 \mathrm{aA}$ \\
\hline *Letras iguais minúsculas na mesma linha ou maiúsculas na coluna, indicam que não houve diferença \\
significativa ao nível de 1\% de probabilidade, pelo teste $\mathbf{t}$ de Student
\end{tabular}

sistema com TBA foi inferior à do sistema TFC, demonstrando sua eficiência na diminuição da temperatura interna da cobertura, sendo que esta diferença foi de 1,2 e $1,4{ }^{\circ} \mathrm{C}$ entre os sistemas nos turnos manhã e tarde, respectivamente.

Os resultados encontrados para a TFC, seja no período da manhã ou no da tarde, foram inferiores aos citados por Furtado et al. (2002) em galpões de frangos de corte cobertos com telhas de fibrocimento, e diferentes sistemas de acondicionamento térmico (ventilação artificial, ventilação artificial e nebulização e ventilação artificial e aspersão sobre a cobertura). Comparando-se os valores do sistema TFC com os relatados por Furtado et al. (2003), em que os autores pesquisaram a temperatura interna da telha em galpões de frangos de corte com e sem pintura na sua face externa, nota-se que os valores médios encontrados no presente trabalho também foram inferiores aos relatados por esses autores, nos dois tipos de cobertura.

Têm-se que, no sistema TBA, apesar da diminuição na temperatura interna da telha, este fato não consegue, isoladamente, promover diminuição substancial nas condições ambientais do aprisco. Furtado et al. (2002) também observaram que a aspersão de água sobre a cobertura de galpões para frangos de corte, com telhas de fibrocimento, provocava diminuição na temperatura interna da telha mas não conseguia diminuir os índices de conforto térmico dentro dos galpões.

A Tabela 3 apresenta as médias da temperatura retal (TR) e da freqüência respiratória (FR) dos ovinos Santa Inês, medidas no horário das 9:00 e 15:00 h, nos dois sistemas de acondicionamento térmico. Constata-se, em relação à temperatura retal, que não houve diferença significativa a nível de $5 \%$ de probabilidade entre os sistemas telha de barro e telha de fibrocimento nem entre os turnos manhã e tarde. Esses índices demonstram que, no período da tarde, mesmo sob condições de estresse térmico, já que a TA, Tgn, ITGU e a CTR estiveram fora da zona de conforto térmico, os ovinos Santa Inês conseguem manter a temperatura corporal dentro dos limites considerados normais. De acordo com Dukes \& Swenson (1996) a TR normal em caprinos oscila de 38,5 a 39,5

Tabela 3. Médias* da temperatura retal (TR) e freqüência respiratória (FR) dos ovinos Santa Inês nas duas coberturas: telha de barro e telha (TBA) e de fibrocimento (TFC)

\begin{tabular}{lccccc}
\hline \multirow{2}{*}{ Sistemas } & \multicolumn{2}{c}{$\begin{array}{c}\text { Temperatura retal } \\
\left({ }^{\circ} \mathrm{C}\right)\end{array}$} & & \multicolumn{2}{c}{$\begin{array}{c}\text { Freqüência Respiratória } \\
\text { (movimentos por min) }\end{array}$} \\
\cline { 2 - 3 } \cline { 5 - 6 } & Manhã & Tarde & & Manhã & Tarde \\
\hline Telha de barro & $39,3 \mathrm{aA}$ & $39,5 \mathrm{aA}$ & & $42,1 \mathrm{aA}$ & $51,3 \mathrm{bA}$ \\
Telha de fibrocimento & $39,5 \mathrm{aA}$ & $39,6 \mathrm{aA}$ & $44,8 \mathrm{aB}$ & $53,9 \mathrm{bA}$ \\
\hline $\begin{array}{l}\text { * Letras minúsculas iguais nas mesmas colunas e maúsculas nas linhas, identificam que não houve } \\
\text { diferença significativa a nivel de } 5 \% \text { de probabilidade, pelo teste } \mathrm{t} \text { de Student }\end{array}$
\end{tabular}

${ }^{\circ} \mathrm{C}$ e vários fatores são capazes de causar variações normais na temperatura corporal, entre os quais estão idade, sexo, estação do ano, período do dia, exercício e ingestão de alimentos. As médias da TR verificadas no dois turnos, apresentaram-se próximas às descritas por Arruda \& Pant (1985), Santos et al. (2005) e Souza et al (2005), sendo que os valores encontrados no período da manhã foram superiores aos relatados por Silva et al. (2004).

Quanto à freqüência respiratória $(\mathrm{FR})$ dos ovinos Santa Inês, constata-se que, nos dois sistemas, ocorreu diferença entre o turno da manhã e da tarde, e no aprisco com cobertura com telha de barro, os animais apresentaram os menores valores. O período da tarde mostrou valores de TA, Tgn, ITGU e UR que podem ser considerados fora da zona de conforto térmico, caracterizando uma situação de desconforto para os animais, os quais conseguiram manter a TR constante, porém aumentaram a FR, que ficou acima da normal descrita para a espécie. Quando ocorre uma elevação acentuada na temperatura ambiente, os mecanismos termorregulatórios são acionados, aumentando a perda de calor na forma insensível, através da sudorese, e aumento da FR. Brasil et al. (2000) trabalhando com caprinos em condições de termoneutralidade e sob estresse térmico, verificaram haver variação da FR em relação ao período do dia, sendo a média do turno da tarde superior à do turno da manhã. De acordo com Blood \& Henderson (1978) um aumento elevado da temperatura pode dobrar a freqüência respiratória normal em ovinos.

A freqüência respiratória para caprinos é considerada normal quando apresenta valor médio de 15 movimentos respiratórios por minuto, podendo esses valores variar entre 12 e 25 movimentos por minutos e serem influenciados pelo trabalho muscular, temperatura ambiente, ingestão de alimentos, gestação, idade e tamanho do animal (Kolb, 1987). Comparandose esses valores com os encontrados por Silva et al. (2004), seja no período da manhã como no da tarde, nota-se que eles foram superiores aos encontrados por esses autores e também aos relatados por Santos et al. (2005) em caprinos mantidos à sombra.

As médias do ganho de peso total (GPT), ganho de peso diário (GPD), conversão alimentar (CA) e consumo de matéria seca (CMS) dos animais nos dois sistemas de acondicionamento térmico, estão apresentados na Tabela 4, constatando-se que os valores de GPT, GPD, CA e CMS não sofreram diferenças significativas $(\mathrm{P}>0,05)$ entre os dois sistemas de acondicionamento térmico, demonstrando que os ovinos Santa Inês, mesmo passando por período de desconforto térmico, conseguiram manter os índices produtivos dentro de uma faixa que pode ser considerada boa para as condições do semi-árido nordestino (Perez et al., 1995 e Barros et al., 1999).

Tabela 4. Médias* do ganho de peso total (GPT), ganho de peso diário (GPD), conversão alimentar (CA) e consumo de matéria seca (CMS) dos animais, para os dois sistemas de acondicionamento térmico

\begin{tabular}{lcccc}
\hline Sistemas & GPT $(\mathrm{Kg})$ & GPD $(\mathrm{g})$ & CA & CMS (\%) \\
\hline Telha de barro & $7,34 \mathrm{a}$ & $0,175 \mathrm{a}$ & $7,45 \mathrm{a}$ & $4,26 \mathrm{a}$ \\
Telha de fibrocimento & $7,87 \mathrm{a}$ & $0,187 \mathrm{a}$ & $8,86 \mathrm{a}$ & $4,30 \mathrm{a}$ \\
\hline
\end{tabular}


Magalhães et al. (2001) trabalhando com o efeito do estresse climático em ovinos, concluíram que animais mantidos em ambientes parcialmente sombreados apresentaram ganho de peso superior àqueles que receberam radiação direta, destacando-se a importância das instalações para alcançar boa produtividade. A conversão alimentar e o consumo de matéria seca, também podem ser considerados boa, para ovinos Santa Inês permanecendo, portanto, dentro da média nacional para este tipo de animal.

\section{CONCLUSÕES}

1. Os apriscos cobertos com telha de barro foram mais eficientes na redução da temperatura interna da telha, mas não se mostraram eficientes na redução dos índices de conforto térmico, em nível do centro de massa dos ovinos, que foram semelhantes nos dois galpões, ocorrendo elevação nesses índices, no período da tarde.

2. Os animais conseguiram manter a temperatura retal dentro dos limites normais, sendo que aqueles criados no aprisco com telha de fibrocimento apresentaram, no período da tarde, freqüência respiratória superior à dos animais criados no aprisco com telha de barro.

3. O confinamento de ovinos Santa Inês é economicamente viável na região semi-árida nordestina, já que o ganho de peso dos animais foi satisfatório durante o período do experimento.

\section{LITERATURA CITADA}

Arruda, F.A.V.; Pant, K.P. Tolerância ao calor de caprinos e ovinos sem lã em Sobral. Pesquisa Agropecuária Brasileira, Brasília, v.19, n.3, p.379-385, 1985.

Baêta, F.C.; Souza, C.F. Ambiência em edificações rurais conforto animal. Viçosa: UFV, 1997, 246p.

Barros, N.N.; Figueiredo, E.A.P.; Barbieiri, M.E. Efeito do genótipo e da alimentação no desempenho de borregos de cruzamento industrial em confinamento. Revista Científica de Produção Animal, Teresina, v.1, n.1, p.59-67, 1999.

Barros N.N.; Simplício, A.A. Terminação de borregos em confinamento no Nordeste do Brasil, no período seco. Sobral: EMBRAPA-CNPC. 1996. 28p. Circular Técnica, 12

Blood, D.C.; Henderson, J.A. Medicina veterinária. 4.ed. Rio de Janeiro: Editora Interamericana, 1978. 1000p.

BNB. Banco do Nordeste do Brasil. Agenda do produtor rural do Nordeste. Fortaleza: BNB. Ambiente de Implementação de Programas, 1999.....p.

Brasil, L.H.A.; Wechessler, F.S.; Bacarri Júnior, F.; Gonçalves, H.C.; Bonassi, I.A. Efeito do estresse térmico sobre a produção, composição química do leite e respostas termorreguladoras de cabras da raça Alpina. Revista Brasileira de Zootecnia, Viçosa, v.29, n.6, p.1632-1641. 2000.

Brion, A. Vademecum del Veterinário. 2.ed. Barcelona: Gea, 1964, 732p.

Dukes, H.H.; Swenson, H.J. Fisiologia dos animais domésticos. 11.ed. Rio de Janeiro: Afiliada. 1996. 856p.

Ferreira, P.V. Estatística experimental aplicada à agronomia, 2.ed. Maceió: Editora Universitária, 1996, 604p.
Furtado, D.A.; Azevedo, P.V.; Azevedo, M.A.; Vieira, L.G. Temperatura interna da telha de cimento amianto em aviários com e sem pintura na sua face externa. In. Congresso Brasileiro de Meteorologia, Foz do Iguaçu, 2003. Anais .... Foz de Iguaçu : SBMET, 2003, CD-Rom.

Furtado, D.A.; Santos J.T.; Nascimento, J.W.B.; Azevedo, M.A.; Azevedo, P.V. Temperatura da telha de cimento amianto em aviários com diferentes sistemas de acondicionamento. In: Congresso Brasileiro de Engenharia Agrícola, 31, 2002. Salvador, Anais ... Salvador: SBEA, 2002. CD-Rom.

Hafez, E.S.E. Reprodução animal. 6.ed. Barueri: Editora Manole Ltda. 1995. 598p.

Kolb, E. Fisiologia veterinária. 4.ed. Rio de Janeiro, Guanabara Koogan. 1987. 1115p.

Magalhães, J.A.; Costa, N.L.; Pereira, R.G.A.; Townsend, C.R. Desempenho produtivo e reações fisiológicas de ovinos deslanados mantidos sob seringal (Havea brasiliensis). Revista Cientifica de Produção Animal, Teresina, v.3, n.1, p.77-82, 2001.

McDowell, R.G. Improvement of livestock production in war climates. San Francisco: W.H. Freeman and Company, 1972, $771 \mathrm{p}$.

Mota. F.S. Climatologia zootécnica. Pelotas: Edição do autor, 104p. 2001.

Nääs, I.A. Princípios de conforto térmico na produção animal. São Paulo:Editora Ícone, 1989. 183p.

Perez, J.R.O.; Furusho, I.F.; Oliveira, M.V.M. Avaliação do desenvolvimento de cordeiros Santa Inês e cruzas Texet x Santa Inês e Texet x Bergamácia, até o desmame. In: Manejo e Reprodução, 1995, Brasília. Anais... Brasília, 1995. 258p.

Rosa, Y.B.C.J. Influência de três materiais de cobertura no índice de conforto térmico em condições de verão, para Viçosa MG. Viçosa: UFV, 1984. 77p. Dissertação Mestrado

Santos, F.C.B.; Sousa, B.B.; Alfaro, C.E.P.; César, M.F.; Pimenta Filho, E.C.; Acosta, A.A.A.; Santos, J.R.S. Adaptabilidade de caprinos exóticos e naturalizados ao clima semi-árido do nordeste brasileiro. Ciência Agrotécnica, Lavras, v.29, n.1, p.142-149. 2005.

Silva, F.L.R.; Figueiredo, E.A.P.; Simplício, A.A. Parâmetros de conforto genéticos e fenotípicos para pesos de caprinos nativos e exóticos criados no Nordeste do Brasil, na fase de crescimento. Revista da Sociedade Brasileira de Zootecnia, Viçosa, v.22, n.2.p.350-359. 1993.

Silva, G.A.; Sousa, B.B.; Alfaro, C.E.P.; Silva, E.M.N.; Azevedo, S.A.; Neto, J.A.; Silva, R.M.N. Efeito da época do ano sobre os parâmetros fisiológicos de caprinos no semi-árido. In: SIMCRA - Simpósio de Construções Rurais e Ambiência. Campina Grande, 2004. Anais.... Campina Grande:UFPB, 2004. CD-Rom

Souza, D.E.; Souza, B.B.; Souza, W.H.; Cezar, M.F.; Santos, J.R.S.; Tavares, G.P. Determinação dos parâmetros fisiológicos e gradiente térmico de diferentes grupos genéticos de caprinos no semi-árido. Ciência Agrotécnica, Lavras, v.29, n.1, p.177-184. 2005.

Viana, J.A.C. Desafios e potencialidades da produção animal nos trópicos e subtrópicos: reflexões produtivas. In: Reunião Anual da Sociedade Brasileira de Zootecnia, 27, 1990, Campinas. Anais...Campinas:SBZ. 1990. p.640-679. 